\title{
A coca e os direitos da Mãe Terra: uma ontologia latino-americana
}

\author{
Maria Eugenia Flores \\ Doutoranda em Antropologia \\ Instituto de Investigaciones en Ciencias Sociales y \\ Humanidades - Consejo de Investigación Universidad Nacional de \\ Salta (ICSOH-CONICET - CIUNSa)
}

\begin{abstract}
Ana Gretel Echazú
Professora temporária do Departamento de Antropologia Pós-Doutoranda do Programa de Pós-Graduação em Saúde

Coletiva

Universidade Federal do Rio Grande do Norte
\end{abstract}

Resumo: O presente artigo analisa aspectos jurídico-políticos da relação entre a planta da coca (Erythroxylum coca) com a Pachamama, conceito andino traduzido aqui como "Mãe Terra". Focaliza-se nas implicações das reformas constitucionais dos países andinos do Equador e da Bolívia na primeira década de 2000 percebendo-as como a refundação política dos laços entre a humanidade e seu entorno. Posteriormente, apresentamos a paisagem etnográfica das festas da Pachamama em comunidades indígenas e mestiças periurbanas do Noroeste Argentino, área que tem se reivindicado como parte da comunidade de países andinos. Propomos aqui que a compreensão do vínculo entre a planta da coca e a Pachamama estabelece uma ponte entre princípios jurídicos abstratos e o cotidiano. Na relação ontológica entre seres humanxs e plantas, elas se assumem enquanto sujeitxs com agência e poder transformador. Colocamos aqui que a compreensão desse diálogo enraizado é fundamental para abrir caminho às dimensões jurídicas, sociais, pedagógicas e epistemológicas que valorizam a sagrada existência da Pachamama assim como aquelas plantas que encarnam a mais vibrante expressão da sua agência.

Palavras-chave: coca; Andes; ontologia; Mãe Terra; direitos. 


\title{
Coca and the rights of Mother Earth: a Latin American ontology
}

\begin{abstract}
This article discusses juridical and political aspects of the relationship between the coca plant (Erythroxylum coca) and Pachamama, which is here translated as Mother Earth. It focuses on the implication of the constitutional reform that took place in the Andean countries of Ecuador and Bolivia in the first decade of 2000 as a political refoundation of the bonds between what is human and its environment. It also presents a narrative on the ethnographic landscapes at festivities dedicated to Pachamama in peri-urban indigenous and mestizo communities Northwestern Argentina, an area that has been claimed as a part of the of the Andean community. We propose that an understanding of the bond between the coca plant and Pachamama can establish a bridge between abstract legal principles and daily life. In the ontological relationship between human beings and plants, plants are understood as subjects with agency and transformative power. We argue that visualizing this situation is key in order to open a discussion about juridical, social, pedagogical and epistemological dimensions that value the sacred existence of Pachamama as much as the plants that embody the most vibrant expression of its agency.
\end{abstract}

Keywords: coca; Andes; ontologies; Mother Earth, rights.

\section{Coca y los derechos de la Madre Tierra: una ontología de América Latina}

Resúmen: El presente artículo analiza aspectos jurídico-políticos de la relación entre la planta de la coca (Erythroxylum coca) con la Pachamama, concepto andino traducido aquí como el de Madre Tierra. Se focaliza en las implicaciones de las reformas constitucionales de los países andinos Ecuador y Bolivia en la primera década de 2000 como refundación política de los lazos entre la humanidad y su entorno. Posteriormente, se presentan los paisajes etnográficos de las fiestas de la Pachamama en comunidades indígenas y mestizas periurbanas del Noroeste Argentino, área que se ha reivindicado como parte de la comunidad de países andinos. Proponemos aquí que la comprensión del vínculo entre la planta de la coca y Pachamama establece un puente entre principios jurídicos abstractos y lo cotidiano. En la relación ontológica entre seres humanxs y plantas, ellas se asumen como sujetxs con agencia y poder transformador. Postulamos aquí que la comprensión de este diálogo enraizado es fundamental para abrir camino a las dimensiones jurídicas, sociales, pedagógicas y epistemológicas que valoran la sagrada existencia de la Pachamama así como a aquellas plantas que encarnan la más vibrante expresión de su agencia.

Palabras clave: coca; Andes; ontologías; Madre Tierra; derechos. 


\section{Ontologias latino-americanas e os direitos das plantas}

No presente trabalho apresentaremos uma problematização que é, ao mesmo tempo, ontológica, política e epistemológica sobre a folha de coca, a Pachamama e as comunidades conectadas com elas ${ }^{1}$. Nossa contribuição teórica e metodológica é inspirada em alguns aspectos da postura ontológica do perspectivismo ameríndio que se centra nas relações entre humanos e não humanos. Porém, essa inspiração é seletiva, e questiona a tendência de uma grande parte das contribuições antropológicas do perspectivismo ameríndio que priorizam os aspectos ontológicos sobre os epistemológicos, políticos e históricos, além de dar ênfase à procura de um mesmo pano de fundo cosmológico como modelo para a diversidade humana e vegetal da nossa América Latina.

Nossa proposta é focalizar no espaço geográfico, político e existencial das ontologias latino-americanas ligadas à relação entre seres humanxs ${ }^{2}$ e plantas. Ela nasce a partir do mosaico de iniciativas produzidas a partir de ações de órgãos governamentais, movimentos sociais e trabalhos de base com povos indígenas e mestiços da América Latina, e nos convida a focarmos em materiais etnográficos de comunidades humanas e vegetais particulares. No caso desse artigo, serão as terras altas andinas. Nelas, a relação entre o mundo do que é humano com o mundo das plantas é horizontal e transversal: ela não está feita de substâncias definidas e permanentes em sóbria interação, mas de conexões fluidas, diálogos transversais e ligações inter-substanciais. Da mesma maneira em que as plantas se ligam transversalmente com o mundo do que é humano, isso mesmo acontece com os xs animais, espíritos e lugares. De acordo com essa compreensão, o que existe no mundo é feito também de outros mundos, muitos deles invisíveis. A conexão entre esses mundos é propiciada por elementos catárticos, bisagras vivas, porta-vozes que falam línguas inaudíveis. Dentro das ontologias estudadas, as plantas assumem um lugar privilegiado na consecução dessa tarefa.

As plantas são compreendidas como sujeitxs capazes de ação, influência e transformação: verdadeirxs sujeitxs políticxs. A sua capacidade de ação, de influência no mundo; a sua dignidade, a sua necessidade de proteção são qualidades que dão verdadeiramente a abertura para uma reflexão de âmbito jurídico. De fato, o caso da coca (Erythroxylum coca) em países andinos como Bolívia, Argentina, Peru e Colômbia é muito expressivo no que concerne à força que uma planta pode adquirir na cristalização da identidade política de um povo. As leis relativas à Pachamama são a mais contundente manifestação disso.

$\mathrm{Na}$ América Latina, conceitos advindos de cinco séculos de colonização convivem com sintagmas do profundo passado pré-hispânico, que são os que alimentam as diversas formas de resistência em cada momento do presente. Vale aqui uma ressalva. No presente texto, usamos de forma equivalente o conceito indígena quéchua de Pachamama com a ideia ocidental de Mãe Terra,

${ }^{1}$ Agradecemos a cuidadosa leitura do manuscrito em português por parte da nossa colega Cristina Diógenes.

2 No que respeita ao gênero da nossa escrita acadêmica, optamos pela linguagem inclusiva dos marcadores de gênero no texto, escolhendo o grafismo " $x$ " e substituindo assim as desinências masculinas ou femininas relativas a artigos e substantivos. Assim, em lugar de "humanos", colocamos "humanxs"; em lugar de "filósofos", consignamos "filósofxs" e assim por diante. 
assumindo uma tradução um tanto inexata da própria noção indígena de Pachamama.

A região dos Andesà qual pertence o Noroeste da Argentina conta com comunidades indígenas quéchuas, aymaras, calchaquíes, guaraníes e kollas, assim como comunidades mestiças derivadas da relação entre essas comunidades e colonos espanhóis durante a conquista Sul-Americana. Nessas comunidades, Pachamama é um conceito multidimensional que alude à terra, tempo, universo, local e à própria mãe. Ela não se localiza em lugares específicos, nem pode ser captada só com olhos humanos. Seu sutil movimento criativo nas múltiplas esferas do que existe a torna fonte da vida. Porém, a Pachamama não é uma entidade sempre doadora, generosa e aberta. Ela também possui um lado conflituoso, doloroso e cruel, ligado à extinção e à morte. A ambiguidade do conceito de Pachamama nos faz ressaltar a necessidade de sermos cuidadosxs na hora de projetar a tradução vis à vis do mesmo como "Mãe Terra". Ao ativarmos a expressão "Mãe Terra", lançamos mão da vantagem pedagógica de alcançar uma melhor compreensão de potenciais leitorxs cujas referências culturais se encontram distantes do sistema andino de conhecimentos sobre o mundo.

\section{A Mãe Terra como sujeito político: os casos do Equador e da Bolívia}

Os direitos da natureza testemunham uma mudança de paradigma civilizatório que questiona as lógicas antropocêntricas, evoluindo juridicamente para concepções nas quais os regimes de direitos são estendidos e transversalizados. Isso não acontece em um vácuo histórico, mas sim no contexto da crise ambiental mais dolorosa que a humanidade moderna provavelmente já conheceu.

No cenário internacional, uma mensagem de cautela emergiu há décadas. No ano 1986, as Nações Unidas proclamaram uma Declaração pelo Direito Ambiental, em que se destaca com vigor uma concepção holística dos problemas ambientais aplicada ao âmbito das políticas internacionais. Naquele momento então, se declarou que "as próximas décadas serão cruciais para o futuro da humanidade" (Buntland Report, 1987: 1; tradução nossa) e se incitou a ação conjunta entre governos, empresas e sociedade civil, assim como a uma percepção unificada dos problemas através de um olhar transversal que fosse capaz de atravessar as diversas disciplinas do saber.

No ano de 2008, o parlamento do Equador ativou uma profunda reforma política na direção do reconhecimento de si próprio como um estado intercultural e plurinacional. Aqui, a Mãe Terra merece um capítulo especial na Constituição e é considerada um verdadeiro sujeito legal, da mesma forma que xs sujeitxs e coletividades humanxs (BARIÉ, 2014). No preâmbulo da Constituição do Equador consta a máxima: "celebrando a natureza, a Pachamama, da qual somos parte e que é vital para nossa existência" (Constitución de la República de Ecuador 2008:1; tradução nossa). Depois, afirma-se a necessidade da construção de "uma nova forma de convivência cidadã, em diversidade e harmonia com a natureza, para alcançar o bom viver, o sumak kawsay" (Ídem 2008: 1; tradução nossa). O conceito de "Sumak Kawsay" é inspirado na cosmovisão indígena e apresenta uma multiplicidade de aspectos 
inter-subjetivos relativos a valores humanos. Ele é vertido desde os saberes populares de base, emergindo como o "viver bem" de uma visão que integra direitos e responsabilidades dxs seres humanxs para com elxs mesmxs de maneira simultânea com os da própria Mãe Terra.

No ano de 2010 o povo boliviano, através de seu parlamento, instaurou a Lei dos Direitos da Mãe Terra, aderindo ao conceito de Pachamama a partir da convergência entre políticxs indígenas e não-indígenas (DE LA CADENA, 2012). $\mathrm{Na}$ lei constam não somente as restrições à ação predatória da humanidade sobre o meio ambiente, mas também estímulos a procederes ambientais responsáveis. Ali se declara: "O Estado incentivará às pessoas naturais e jurídicas e aos coletivos para protegerem a natureza, e promoverá o respeito a todos os elementos que formam um ecossistema" (Ley de la Madre Tierra 2010:1; tradução nossa). Neste breve documento aparece retratado o viés jurídico de uma prática cultural ancestral: a da contemplação ativa da Pachamama. Ela não é uma divindade que se adora: ela é uma divindade que se pisa, que se ingere, na qual se deita e sobre a qual se morre. Ciente da complexidade dessa relação, no documento aparecem consignadas uma série de princípios de cumprimento obrigatório, entre os quais se contam: harmonia (as atividades humanas devem estar em equilíbrio com os ciclos e processos inerentes à Mãe Terra), bem coletivo (o interesse da sociedade, no marco dos direitos da Mãe Terra, prevalece em toda atividade humana e acima de qualquer direito adquirido), garantia de regeneração (garantir a absorção de danos, adaptação às perturbações e regeneração, considerando limites da ação humana na complexidade da teia de sistemas vivos); respeito e defesa dos direitos (correspondentes tanto ao Estado quando ao povo boliviano), não mercantilização (nem dos sistemas de vida nem dos processos que a sustentam) e interculturalidade (considerando a importância do diálogo, reconhecimento, respeito e proteção da teia de vida circundante).

Ainda que ela não seja considerada uma divindade inalcançável, isso não faz dela uma entidade menos venerável. De acordo com a cosmovisão dos diferentes povos camponeses e indígenas andinos, ela é sagrada. Por sua vez, todxs xs humanxs, pelo simples fato de formarem parte dela, são veneráveis também. Na lógica do ciclo de vida e morte, a terra alimenta a comunidade e a comunidade é alimentada pela terra. Para proteger esse movimento, é preciso que não existam somente direitos que contemplem aos seres humanxs, mas também que existam direitos que contemplem àquela entidade que dá origem e continuidade à própria humanidade: a Mãe Terra. Na Lei dos Direitos da Mãe Terra, consta que ela tem direito: “à vida (...), à diversidade da vida (...) à água (...) ao ar limpo (...) ao equilíbrio (...) à restauração (...) a viver livre de contaminação" (Ley de los Derechos de la Madre Tierra, 2010: 2; tradução nossa).

No próprio preâmbulo da Constituição Boliviana, submetida ao voto popular também no ano de 2009, afirma-se: "Cumprindo com o mandato de nossos povos, com a fortaleza de nossa Pachamama e graças à Deus, refundamos Bolívia" (Constitución Política del Estado Boliviano, 2009: 8; tradução nossa). Por sua vez, o artigo número $33^{\circ}$ do mesmo texto prescreve que:

[...] as pessoas têm direito a um meio ambiente saudável, protegido e equilibrado. $\mathrm{O}$ exercício desse direito deve permitir aos indivíduos e coletividades das presentes e 
futuras gerações, ademais de outros seres vivos, se desenvolver de maneira normal e permanente. (Ídem, 2009: 22; tradução nossa)

\section{$\mathrm{O}$ artigo $34^{\circ}$ complementa o anterior dispondo que:}

[...] qualquer pessoa, a título individual ou em representação de uma coletividade, está facultada para exercer as ações legais em defesa do meio ambiente, sem prejuízo da obrigação das instituições públicas de agir frente aos atentados contra o meio ambiente”. (ZAFFARONI, 2012: 53)

Desta maneira, se institui um direito horizontal e ampliado que coloca no mesmo nível a dignidade da Mãe Terra com a de seus e suas filhxs.

Nesse contexto, a planta da coca observa um lugar especial. De forma simultânea com o reconhecimento da Pachamama como sujeitx de direitos, uma série de documentos expressam a atenção oficial voltada para a planta da coca. Merece especial destaque o protocolo do Ministério de Relações Exteriores da Bolívia. Este documento de 2009, cujo título pode ser traduzido como "Aprendizagem de Novos Protocolos: O Akhulli. Folha de Coca na diplomacia do Povo", relata as várias maneiras de estabelecer uma relação com a coca nas culturas Quechua e Aymara, se centrando especialmente nos usos públicos da mesma. Por sua vez, a coca não só proporciona visibilidade aos movimentos de reivindicação indígena: ela também afeta as relações internacionais e as demandas geopolíticas mais urgentes da humanidade hoje. A manifestação pública da compreensão sagrada e ritual do consumo de coca torna possível a modificação do traço estigmatizante marcado pela guerra contra o narcotráfico instituída violentamente no século XX (PÉREZ MENDOZA, 2016).

A Pachamama pode ser compreendida como uma reverberação do próprio núcleo do sistema de práticas ecológico-sociais dos povos andinos. O que foi expresso nas vanguardistas reformas do Equador e da Bolívia através da enunciação das bases afetivas da resistência indígena e camponesa foi uma ação absolutamente pioneira no planeta. A mesma germinou rapidamente, sendo replicada em outros cenários de forma especular. No dia 20 de abril de 2010, em Cochabamba, Bolívia, teve lugar a Conferência Mundial sobre Mudança Climática e Direitos da Mãe Terra, onde foi redigido um projeto de Declaração Universal dos Direitos da Mãe Terra, que foi ratificado no Panamá na Assembleia Ordinária do Parlamento Latino Americano, no dia 2 de dezembro de 2011. Essa declaração ultrapassa os limites do que pode ser uma questão lida como "propriamente andina" e estende um chamado à percepção da existência e dignidade da Mãe Terra por parte de todos os povos do planeta. A vocação ecumênica deste movimento afetou como um todo ao movimento global pelos "direitos da natureza", e várias iniciativas adotaram o conceito de "direitos do ecossistema” em países como Turquia, México, Nova Zelândia, Nepal e várias municipalidades dos Estados Unidos nos níveis local, regional e nacional (BARLOW, 2010).

Por sua vez, a própria noção de Pachamama e a influência da coca na vida dos povos não se restringe somente às unidades políticas do Equador e da Bolívia, mas abraça toda a região da Cordilheira dos Andes atravessando também partes da Argentina, Chile, Peru e Colômbia. No ano 2014, o Parlamento Andino reunido em Coroico, Bolívia teve participantes da Colômbia, Peru, Equador e da própria Bolívia. Ali se declarou a folha de coca como patrimônio ancestral e cultural dos povos andinos, ao mesmo tempo em que se 
elaboraram recomendações para a instauração da pesquisa científica e de programas de certificação orgânica da planta.

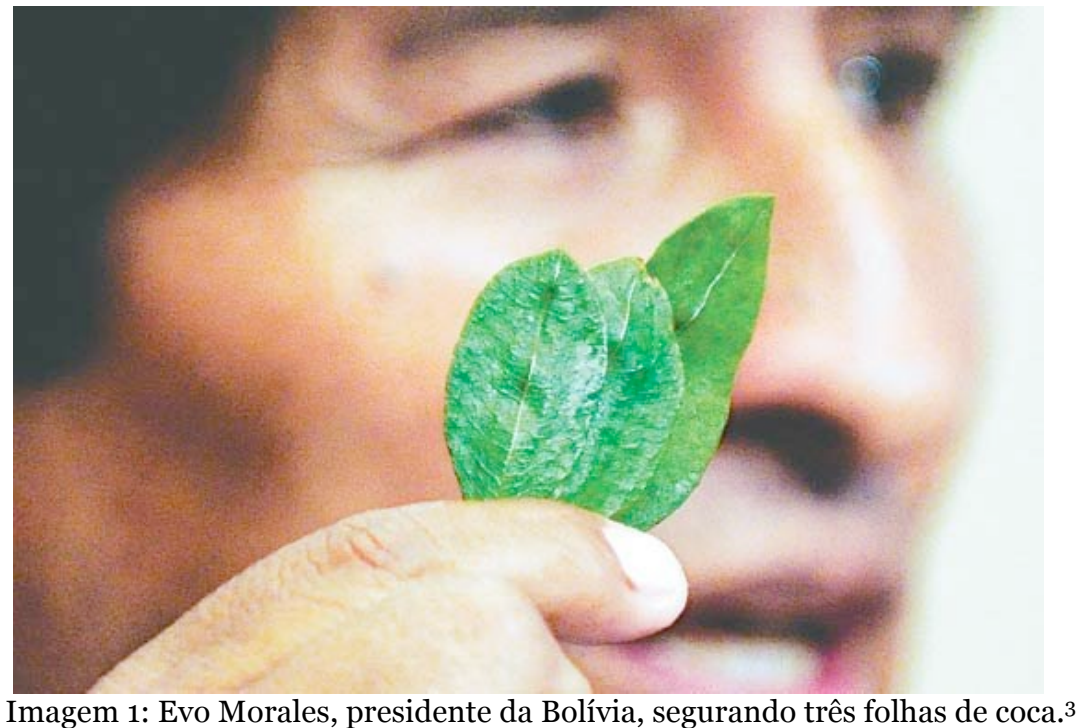

É possível observar que nos casos da Bolívia e do Equador é oficial o reconhecimento dos recursos e conhecimentos "outros" mantidos pelas comunidades indígenas e camponesas de raiz andina durante séculos. Porém, no restante dos países andinos, apesar dos avanços nas discussões, não tem havido ainda uma cristalização institucional acentuada. Porém, o vínculo entre a Pachamama e a Mãe Terra é indiscutível e merece consideração.

Se olharmos para a transformação dos discursos de nível macro, podemos perceber que desde o informe das Nações Unidas até a cristalização do exercício cidadão indígena nas constituições do Equador em 2008 e da Bolívia em 2009, houve tanto continuidades quanto mudanças. É possível observar uma verdadeira continuidade entre os interesses da declaração das Nações Unidas e aqueles das reformas constitucionais do Equador e da Bolívia, mas também devemos destacar há uma importante mudança: o conceito técnico de "meio ambiente" deixou de ter proeminência discursiva para dar lugar àquele, regionalmente significativo, de Pachamama.

Nos dois países a mudança de paradigma tem sido alimentada pelos movimentos de corte anticolonialista e de oposição ao neoliberalismo que impulsionaram as reformas constitucionais desses países, concebidas como verdadeiras re-fundações do Estado. O modelo constitucional pluricultural dos dois países passou a incluir o reconhecimento das identidades étnicas dentro da reforma política e a colocar aos povos indígenas como sujeitxs de direito com crescente participação (BARIÉ, 2014). Esse novo constitucionalismo latinoamericano, definido também como "constitucionalismo ecológico" (ZAFFARONI, 2012) opta por proclamar uma convivência harmônica dxs humanxs com todos os seres viventes dentro da Terra.

3 Extraída de: http://www.elespectador.com/noticias/elmundo/parlamento-andino-declara-coca-patrimonio-culturalde-p-articulo- 477857 
Essa mudança não é pequena, pois ela descreve a transição de uma percepção da natureza de cunho utilitarista para uma pioneira atenção jurídica às maneiras locais de conceber a relação entre tudo o que existe. No contexto atual de indústrias extrativas em expansão, demanda crescente de energia, mercados em pleno desenvolvimento e crise ambiental global, os povos indígenas e camponeses andinos rejeitaram a noção de natureza como recurso. Dessa forma foi colocada sob um olhar crítico a pretensão epistemológica de que a natureza - também definida como meio ambiente ou simplesmente como sistema de recursos - é um objeto passível de ser possuído, interferido e modificado. As demandas das comunidades andinas não devem ser compreendidas como meras expressões culturais, advindas de crenças e reduzíveis a questões de fé: trata-se de diferenças ontológicas, que performam a própria existência humana nestes contextos. No caso particular das demandas em direitos, elas são redigidas desde ontologias políticas diferenciadas (DE LA CADENA, 2012) cuja extensão a antropologia e a filosofia contemporâneas ainda tentam apreender tateando.

\section{Uma cosmopolítica das plantas de poder}

A abordagem cosmopolítica se encontra estreitamente relacionada com o reconhecimento da existência de ontologias plurais a partir das quais são levadas em consideração as existências do humano e a sua relação com o que está além dele (STENGERS, 2014; LATOUR, 2014). Dessa maneira, os rios, montanhas, animais, plantas podem também ser compreendidos como seres em conexão inter-substancial e permanente articulação: um "mundo onde cabem muitos mundos", segundo o lema poético e político do movimento indígena zapatista.

Nessa perspectiva, é impossível conceber a existência de um ambiente natural previamente dado. $\mathrm{O}$ efeito antrópico nas paisagens é intrínseco. $\mathrm{O}$ conceito que coloca a Mãe Terra não só como matéria inanimada, mas também como ser sensível, permite a extensão dessa compreensão para o reconhecimento do restante dos seres sensíveis. Tal exercício de deslocamento epistemológico tem sido definido como herético e radical, sendo situado na produção das epistemologias do Sul (ALBUQUERQUE, 2009; RIVERA CUSICANQUI, 2014). Para tornar tal deslocamento possível, os conceitos devem ser capazes de enfrentar o processo de desconstrução das grandes teorias euro-centradas ao mesmo tempo em que devem poder prestar atenção aos modelos de saber-poder enraizados em espaços-outros, marginais e de resistência.

$\mathrm{Na}$ busca de uma melhor maneira de apreender a agência da coca, escolhemos o conceito matriz de "plantas de poder". Se bem que os conceitos de planta maestra, planta sagrada e planta de poder convivem nas análises antropológicas e se tornam às vezes intercambiáveis (LABATE, CARNEIRO e GOULART, 2005), cada um deles possui particularidades, ênfases e relevos específicos. O conceito de "planta maestra" (planta mestra) não deixa de ser interessante, pois ele se encontra centrado na agência e na possibilidade pedagógica da planta (LUNA, 1986), da mesma forma em que a noção de 
"planta sagrada" também sugere ideias que são chave, pois se encontra focalizada ao redor das noções de veneração ligadas ao tempo longo da tradição indígena (MARTÍNEZ SARASOLA, 2015).

Porém, em virtude da nossa particular proposta, preferimos abraçar a noção de "plantas de poder" pois ela se encontra associada à agência e capacidade de transformação da planta em um contexto social mais do que humano. Tal expressão se origina nos escritos de Carlos Castaneda os quais, além da sua veracidade, impactaram fortemente nas produções tanto da contracultura do Norte quanto do xamanismo mestiço do Sul (LABATE, CARNEIRO e GOULART, 2005). A conotação política do conceito de planta de poder o torna especialmente significativo no caso estudado, beneficiando a discussão jurídica da Pachamama como sujeito de direitos e sua conexão com as plantas como agente essencial nas relações entre a humanidade e a Pachamama.

A partir da ideia de "planta de poder" procuramos a compreensão das plantas como sujeitx de direitos. Ainda quando ela se materializa nas singelas folhas que preparam o chá para curar alguma doença física, as plantas de poder possuem enorme abrangência: elas estão ligadas tanto a processos amplos como a manutenção da ordem cósmica quanto a processos micro como a transformação ritual das pessoas e corpos. A relação com elas se baseia na intersubjetividade e no reconhecimento de uma "inteligência" não-humana na planta (HENMAN, 2008). Elas são ativadas em curas rituais, processos diagnósticos e itinerários terapêuticos. Ao mesmo tempo, elas podem representar emblemas da coletividade determinada, se tornando a própria expressão pública de uma específica vontade de poder.

Nossa intenção aqui é trazer a questão de uma política própria da relação da esfera do humano com aquela das plantas de poder. Certamente, na noção de plantas de poder há implícita uma conexão política com o que é humano. As plantas de poder circulam socialmente: elas são ativadas de acordo com os grupos e setores sociais com os que elas entram em relação. Na longa memória compartilhada, existe uma relação de colaboração, de co-criação da realidade, de co-evolução e de respeito mútuo.

A ideia de pacto define muito bem essa relação, firme e proposital, do que é humano com o mundo das específicas plantas de poder. $\mathrm{O}$ humano transmuta para se aproximar do universo verde da planta. A planta, por sua parte, extravasa o "traje verde" da sua denominação como espécie vegetal: ela faz parte de uma família de entidades invisíveis, onde a aquisição da forma de planta é para essa entidade uma instância entre muitas possíveis. Na história que enlaça comunidades humanas às plantas, há uma mútua subjetivação, um reconhecimento a dois, um co-cultivo, a instituição de um modo de relação específica que dota de singularidade à planta e a quem é humano.

Ao fazermos uma etnografia que tenha por objetivo seguir as plantas, é possível observar os circuitos onde elas passam, ativando sujeitxs e sendo ativadas por elxs, gerando mudanças e contribuindo a manter certa ordem cósmica. Nesse sentido, as plantas de poder podem ser concebidas como portavozes, isto é, como mensageiras que conectam o contexto humano com aqueles relativos às outras formas de existência. Temos encontrado na planta da coca a mais expressiva porta-voz da Pachamama no contexto dos países andinos. Assim, na cosmopolítica andina, a planta da coca se configura como um dos sujeitos cuja voz de resistência é alçada de maneira mais nítida e poderosa. 


\section{Coca e Pachamama: uma relação inter-substancial}

As reflexões que seguem se originam de uma pesquisa antropológica de longa duração no campo do uso social da planta da coca em Salta, na região Noroeste da Argentina (FLORES, 2011; 2012), que dará origem à tese de doutorado de Eugenia Flores, uma das autoras deste texto neste ano de 2017. Esta pesquisa dialoga com a tese de doutorado relativa à planta da ayahuasca na Amazônia do Peru (ECHAZÚ BÖSCHEMEIER, 2015): a partir de discussões comparativas tornou visível que, nas duas cosmologias indígenas e mestiças das terras altas e baixas latino-americanas, as plantas de poder são emblemáticas da relação entre o que é humano com o restante do mundo (ECHAZÚ BÖSCHEMEIER e FLORES, 2016; FLORES e ECHAZÚ BÖSCHEMEIER, 2016). Elas desenham percursos, acessos e possibilidades. Elas conectam com xs sujeitxs que as convocam de formas específicas através de certos rituais. Elas cruzam os espaços sociais unificando ou dividindo as águas do próprio e do alheio. Assim mesmo, elas são agentes de poder, tomando parte integral em processos sociais de continuidade e mudança.

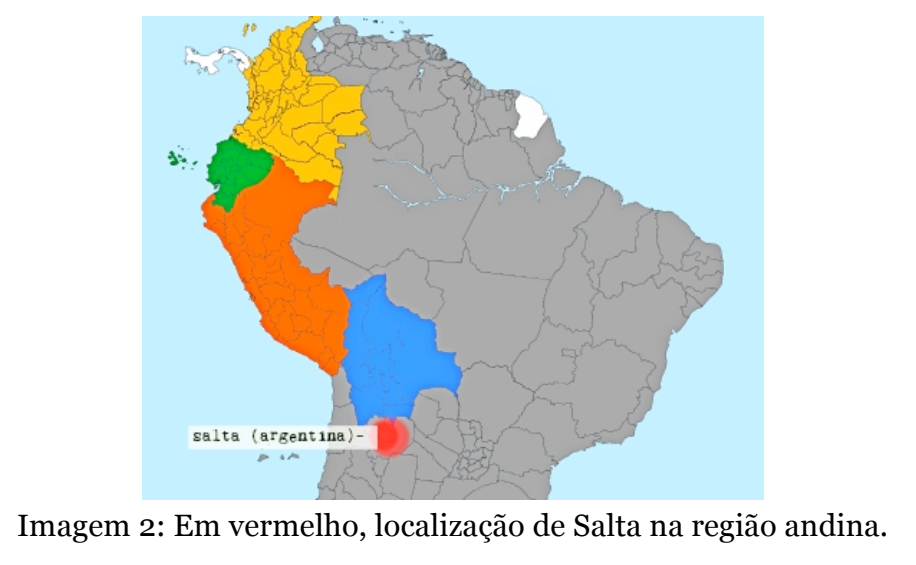

No caso da coca na região Noroeste da Argentina, as folhas desta planta encarnam uma identidade regional: ela atua como uma marca, um signo, um vestígio do que é fazer parte de um todo maior. Esse pertencimento afeta tanto às elites quanto aos povos indígenas e camponeses (RABEY, 1989; ABDUCA, 2010; IGAKI, 2010). Por sua vez a comunicação com as folhas de coca expressa uma simbiose delicada do que é humano com a Pachamama. Esses dois aspectos são complementares e permitem que as pessoas possam vivenciar uma espiritualidade que encaixa sua diversidade nos esquemas da globalização: urbana e rural; anônima e eclética mas, ao mesmo tempo, enraizada e conectada com memórias antigas (CURE, 2015). Dessa maneira, é possível observar que a ideia de Pachamama pode ser compatível com a cultura dominante e hegemônica, mas também que ela pode ser apropriada em outros espaços subalternos e marginais. 
A multiplicidade de experiências que gera a planta da coca em torno de si própria não acaba na sua apropriação pelas diferentes classes sociais. Nos termos de uma dinâmica cósmica que rege a relação humanx-planta, é possível visualizar que ainda que a planta da coca seja reconhecida como doadora de vida e propiciadora de ordem. As análises etnográficas realizadas demonstram que a planta da coca e a entidade da Pachamama estão ligadas por laços muito estreitos: vínculos que são mágicos assim como históricos e geográficos, e que desempenham um papel importante nos rituais que estão sendo ativados no tempo contemporâneo. No que respeita aos vínculos mágicos, a Pachamama aparece como a mais importante deusa da cosmovisão andina: ela mesma é duplo, e seu lado obscuro deve de ser mitigado. Por outra parte, a planta da coca é a filha de Pachamama e ela é quem permite a comunicação dxs sujeitxs humanxs com ela. A pesquisa nos depoimentos escritos da memória histórica demonstra que o culto da Pachamama procede de cenários agrícolas em comunidades rurais, considerando-se que ela mora no cume das montanhas.

Enquanto isso, a coca é um elemento de intercâmbio nos mercados tanto pré-coloniais quanto coloniais: o denominado "trajín" (labuta) da coca nessas áreas geográficas é intenso. A Pachamama se evoca nos cultos da semeadura e sobretudo da colheita, e é ali onde a coca deixa de circular entre mãos humanas para voltar à escuridão cálida da terra. Na presente etnografia, o manuseio humano da coca representa a própria pulsão do trabalho de campo. Na preparação do culto, no mastigar das folhas pelas pessoas presentes, na adivinhação que corre paralelamente e no buraco feito na terra onde se fazem as oferendas à Pachamama, a coca observa um lugar ritual sem dúvidas predominante. Em relação aos laços geográficos, tanto nos Andes Centrais, no Sul Andino quanto no Noroeste Argentino a coca e a Pachamama mostram uma convivência paralela e uma relação de séculos junto às comunidades.

Porém, a coca não é reconhecida como sujeitx de direito. Ela segue fazendo parte da lista de entorpecentes dos códigos penais dos estados a nível global. $\mathrm{O}$ seu status quase legal na Argentina é produto de uma apropriação externa e colonial, que durante décadas atropelou a integridade ontológica dessa planta. $\mathrm{Na}$ absurda guerra às drogas engendrada nos países andinos, xs agentes de segurança dos estados têm vulnerado o direito à vida, à liberdade e à segurança de produtorxs e usuárixs da planta, assim como o acesso à justiça das populações. A proteção ao meio ambiente é outro dos pontos que têm sido vulnerado, tal como é o caso das fumigações com pesticidas tóxicos que provocaram catástrofes humanas e ambientais particularmente na Colômbia (PÉREZ MENDOZA, 2016).

A coca possui uma importância que ultrapassa o ritual privado e o limite geográfico. Ela está presente no centro de um cenário político de impacto em múltiplos níveis da vida social e cultural dos povos andinos (BURMAN, 2011). O status liminar da coca na Argentina é muito expressivo: ela não é legal nem ilegal, mas "quase legal” (ABDUCA, 2010): segundo as disposições nacionais, ela pode ser consumida, mas não comercializada, apesar de possuir uma ampla 
aceitação social devido a seu uso imemorial. Esse uso mostra uma resistência de longa data, na qual xs usuárixs da folha, sem se importar sobre o caráter ilegal dos mercados nos quais ela circula, fazem o possível por obterem ela para realizar suas diferentes atividades.

Enquanto que a coca navega entre duas águas diametralmente opostas, aquela que a coloca como planta sagrada para as comunidades locais especialmente os povos indígenas - e a outra, que a põe como "droga" para a comunidade internacional, a Pachamama ganha uma aceitação mais ampla e cordial. Assim, é possível observar uma crescente oficialização de certos rituais do tronco andino. No ano 2004, a celebração dedicada à Pachamama foi declarada de interesse provincial, quando se instituiu o $1^{\circ}$ de agosto como Dia Provincial da Pachamama. Nesse contexto, se reconhece à Mãe Terra como manifestação divino-pagã que integra a cultura tradicional, oral e popular da região. A festa da Pachamama resulta ser a expressão mais vibrante desse reconhecimento nacional da diversidade regional, e da integração da região Noroeste à unidade cultural maior da comunidade andina (FLORES, 2011).

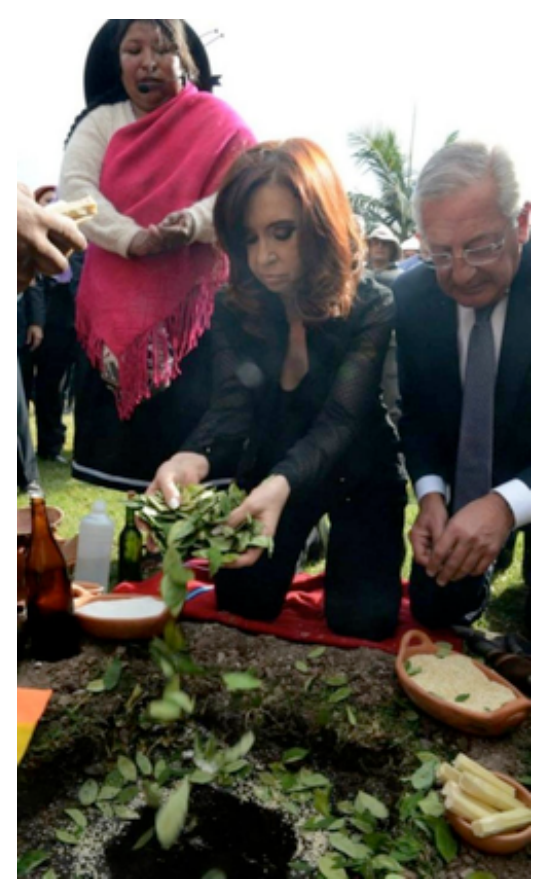

Imagen 3: A Ex-Presidenta argentina Cristina Fernández oferecendo coca à Pachamama.4

4 Disponível em: http://www.cfkargentina.com/fotos/nggallery/main-album/cristina-en-salta-y-jujuy. 


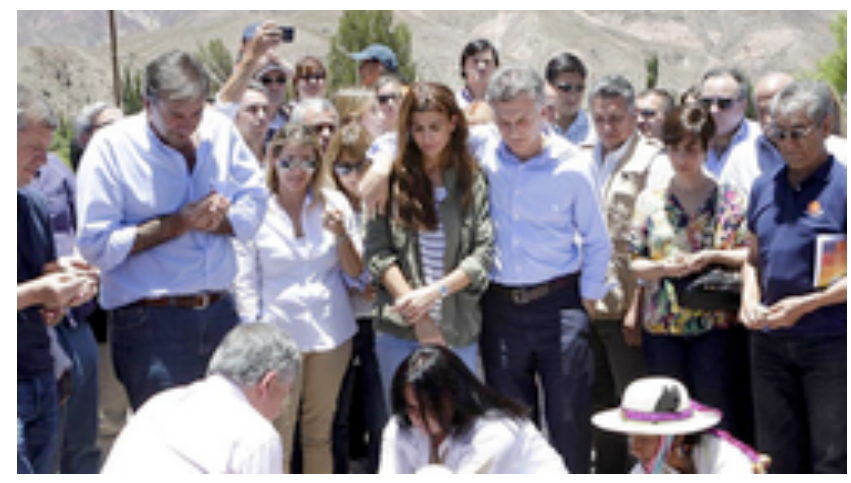

Imagem 4. Atual presidente argentino Mauricio Macri participando do ritual à Pachamama. 5

Nas duas fotografias acima é possível apreciar o gesto dxs presidentes argentinxs dos dois últimos mandatos. Em diferentes anos, elxs viajaram para o Noroeste do país para participar da festividade do culto à Pachamama. Nas duas imagens elxs oferecem, ajoelhadxs, folhas de coca à Mãe Terra. Na primeira fotografia (Imagem 3), do ano 2013, é possível ver a Cristina Fernández. Na segunda fotografia (Imagem 4), tirada neste mesmo ano de 2016, é possível observar ao atual presidente Mauricio Macri. No ritual, ela aparece mais concentrada e entregue à solenidade do momento, enquanto que ele aparece menos curvado e menos presente. Porém, a simples presença de cada um/a delxs na festividade andina é ilustrativa do reconhecimento nacional à Pachamama assim como à coca como planta porta-voz da oferenda humana à Mãe Terra.

Nas primeiras décadas do século XXI, os rituais da Pachamama se tornaram compatíveis com espaços sociais cada vez mais amplos. Na atualidade, um grande número de cidadãos e cidadãs argentinxs e de turistas tanto nacionais quanto estrangeirxs participam dos rituais da Pachamama que se realizam em Salta, pedindo e agradecendo pela saúde da pessoa e seus entes queridos. É assim como próprio momento do festejo da religação com a Mãe Terra na província de Salta está mais vinculado ao calendário de feriados laborais do que aos próprios ciclos astrais, agrícolas e de fertilidade historicamente ligados à Pachamama. Esses rituais ativados nos espaços públicos oficiais irrompem na esfera política reconhecida e, ao mesmo tempo em que reencantam a o cenário da distribuição dos poderes, negociam a representação da natureza de uma maneira que não se restringe àquela científica, nos termos impostos pelo fazer iluminista. Em adição, consideramos que há um processo de desterritorialização e territorialização de tradições que envolve um movimento transfronteiriço, não somente dos rituais, mas também da própria planta da coca como elemento indispensável para a execução dos mesmos. Ao mesmo tempo, é possível observar a articulação com sentidos, práticas e redes de saberes pertencentes a tradições que provêm dos centros das cidades mais populares dos Andes (Lima, Cuzco, La Paz, Potosí, Quito). 
A coca é compartilhada para estimular a socialização do "coqueo" (hábito de chupar a coca). Aqui, cada pessoa tira do interior de uma sacola a quantidade de folhas que acredite ser necessária para iniciar esse momento do "coqueo" coletivo. As folhas são colocadas uma em cima da outra formando um montículo que será introduzido entre os dentes e a bochecha, gerando um suco pela própria força da sucção. Esse suco será lentamente chupado e consumido, formando um bolo, ou "jachu”, de coca cada vez mais compacto. A coca também é usada para ser oferendada individualmente no poço que se faz na terra junto com um cigarro e alguma bebida com conteúdo alcoólico - seja ela vinho, aguardente ou cerveja. No passado, a coca foi protagonista da origem mítica do humano; no presente, ela participa ativamente na reprodução dos ciclos da vida comunitária. O seu lugar não é estático, mas feito a partir de cruzamentos intersubstanciais entre identidades: a coca é, ao mesmo tempo, vegetal, sujeitx, irmã, ferramenta e oferenda. Para algumas pessoas, a folha da coca é filha da Pachamama, enquanto que outrxs apontam que a coca é um espírito aliado que permite a comunicação com a Mãe Terra, uma companhia especial enviada aos e às filhxs da Pachamama. Há outras pessoas que assumem que as folhas da coca são para o ser humano o que o leite materno é para o bebê: nesse caso, a coca assume o lugar de mãe que alimenta, assiste e cura as penas dxs humanxs. Qualquer que seja a imagem evocada para compreender essa relação, é inegável que entre o que é humano, a coca e a Pachamama há uma conexão íntima, fluida e inter-substancial que cria paisagens de direitos não exclusivos, dinâmicos e decididamente transversais.

\section{Uma cosmopolítica vegetal nas folhas da coca}

A agência da coca é relativa aos contextos onde ela prospera e faz sentido. Assumimos que pensar e debater os direitos da coca como entidade com agência é dar atenção ao contato entre uma variedade de mundos, e nesses mundos sobressai a representação de uma cosmopolítica vegetal impressa nos caminhos que traçam suas folhas. Nas terras altas dos Andes, a coca tem crescido junto às comunidades, moldando os saberes locais referentes à relação com a Mãe Terra. A inserção da planta da coca nas demandas pela Mãe Terra como sujeitx de direitos é uma expressão muito viva da cosmopolítica andina: revela uma força transformadora, centrada na própria experiência do ser vegetal, que se encarrega da articulação entre mundos dinâmicos, transversalmente conectados. A planta da coca, mesmo quando conflita com as demandas da "guerra às drogas" encarna uma vida social que é, ao mesmo tempo, ancestral e muito atual. Ela está se tornando cada vez mais visível em novas trajetórias de circulação e movimento, em novos cenários interétnicos, inter-classe e internacionais, que a mostram atuando em um campo político onde abraça dispositivos diplomáticos e expande a sua potencialidade como porta-voz e interlocutora entre mundos diversos. 
Nesse contexto, a experiência constitucional de Equador e Bolívia se tornou pioneira não somente para o restante dos países andinos, mas também para vários outros países do mundo. $\mathrm{O}$ reconhecimento da complexa teia de relações entre seres que se cristaliza naquilo que foi chamado de "Mãe Terra" como sujeitx de poder com direito próprio promete uma abordagem transformadora nas áreas de manejo ambiental e políticas do desenvolvimento. Mas não somente isso: a reconfiguração do olhar que permite a própria compreensão da Mãe Terra como sujeitx de direitos marca uma verdadeira mudança de orientação social, jurídica e epistemológica.

A compreensão do vínculo entre a planta da coca e a Pachamama estabelece uma ponte entre princípios jurídicos abstratos e o cotidiano das pessoas que habitam a terra andina. Fornecer os insumos teóricos e metodológicos para uma antropologia que seja capaz de visualizar esse diálogo enraizado é fundamental para abrir caminho às dimensões jurídicas, sociais, pedagógicas e epistemológicas que valorizam tanto a existência da Pachamama quanto daquelas plantas que, como a coca, encarnam a mais vibrante expressão da sua agência.

\section{Bibliografia}

ABDUCA, R. Acerca del concepto de valor de uso: signo, consumo y subjetividad. La hoja de coca en la Argentina. Tese de doutorado, Antropología. UBA, 2010.

ALBUQUERQUE, M. B. Uma heresia epistemológica: as plantas como sujeitos do saber. Centro de Estudios Sociales Laboratorio Asociado, Universidade de Coimbra, n. 328, 2009, p 1-34.

BARIÉ, G. Nuevas narrativas constitucionales en Bolivia y Ecuador: el buen vivir y los derechos de la naturaleza. Revista Latinoamérica, UNAM, México, $\mathrm{n}$. 2, 2014, p. 9-40.

BARLOW, M. Building the Case for the Universal Declaration of The Rights of Mother Earth. In: Does Nature Have Rights? Transforming Grassroots Organizing to Protect People and the Planet. Quito: Fundación Pachamama, 2010, p. 6-11.

BURMAN, A. Yatiris en el siglo XXI. El conocimiento, la política y la nueva generación. Nuevo mundo, mundos nuevos. Débats. 2011, p. 1-17.

CURE, S. Mambe en contextos urbanos, o la producción de nuevas modalidades de consumo. Mundo Amazónico. v. 6, n. 1, p. 19-45, 2015.

DE LA CADENA, M. Indigenous cosmopolitics: dialogues about the reconstitution of worlds. Universidad de California-Davis, 2012. Disponível em: 
<http://sawyerseminar.ucdavis.edu/files/2012/o1/Sawyer_Seminar_Proposal. pdf $>$ Acesso em 14 de outubro 2016.

DESCOLA, Philippe. Beyond Nature and Culture. Chicago: University of Chicago Press. 2013.

ECHAZÚ BÖSCHEMEIER, Ana Gretel. Corpo de planta. Terapias y magias dxs curiosxs da baixa Amazonia do Peru, sob uma perspectiva situada de gênero e saúde popular. Tese de Doutorado, Antropologia, Universidade de Brasília, 2015.

ECHAZÚ BÖSCHEMEIER, A G; FLORES, E. Derechos de las plantas en contexto: dos ontologías latinoamericanas. No prelo. Revista Vivência, Natal, UFRN, 2016.

FLORES, Eugenia. La Coca en Salta. Tensión entre Tradición y Modernidad. Editorial Académica Española/LAP LAMBERT, Alemanha, 2011.

FLORES, E. Ritualidades contemporáneas en torno a Pachamama. In: Belli, H. e Slavutsky, R. (org.). NOA ofrece. Agroturismo y desarrollo sustentable. Editorial Facultad de Humanidades y Ciencias Sociales-Universidad Nacional de Jujuy, Jujuy, 2012, p. 53-6o.

FLORES, E; ECHAZÚ BÖSCHEMEIER, A G. Ontologías en desigualdad: coca, ayahuasca y la agencia histórica. No prelo. Revista Avá, Universidad de Misiones, Misiones, 2016.

HENMAN, A. A coca como planta mestra: reforma e nova ética. In: Labate, B. Goulart, S., Fiore, M., MacRae, E. e Carneiro, H. (org.) Drogas e Culturas: novas perspectivas. Salvador: EDUFBA. 2008, p 369-381.

IGAKI, A. Desde Ambrosetti hasta Rabey, sobre la coca y el coqueo en Argentina. Revista Andes. Salta, n. 21, 2010, p. 131-146.

LABATE, B; GOULART, S.; CARNEIRO, H. Introdução. In: Labate, Beatriz; GOULART, Sandra. (org). O uso ritual das plantas de poder. Campinas, 2005, p. 29-55.

LATOUR, B. ¿El cosmos de quién? ¿Qué cosmopolítica?: Comentarios sobre los términos de paz de Ülrich Beck. Revista Pléyade.Santiago de Chile, n. 14, 2014, p. 43-59.

LUNA, Eduardo. Vegetalismo: shamanism among the mestizo population of the Peruvian Amazon. Stockholm, Almqvist and Wiksell International, 1986.

MARTÍNEZ SARASOLA, C. Las plantas sagradas según la cosmovisión originaria. In: Agencia de noticias San Luis. Notícia do 26/12/2015. Disponível em: $\quad<$ http://agenciasanluis.com/notas/2015/12/26/las-plantas-sagradassegun- la-cosmovision- originaria/ \&gt> . Acesso em 26 dezembro 2017. 
PÉREZ MENDOZA, Jessica Brenda. Política y legislación internacional sobre la hoja de coca: Lecciones del caso boliviano para América Latina. Salta, Purmamarka Ediciones, 2016.

RABEY, M. Legalidad e ilegalidad del coqueo en Argentina. In: La coca. Tradición, rito, identidad. México: Instituto Indigenista Interamericano, 1989, p. 35-77.

STENGERS, I. La propuesta cosmopolítica. Revista Pléyade.Santiago de Chile, n. 14, 2014, p. 17-41.

ZAFFARONI, Eugenio Raúl. La pachamama y el humano. Buenos Aires, Colihué, 2012.

VIVEIROS DE CASTRO, E. Os pronomes cosmológicos e o perspectivismo ameríndio. Mana, Rio de Janeiro, n 2 (2), 1996, p 115-144.

VIVEIROS DE CASTRO, Eduardo. A inconstância da alma selvagem. Rio de Janeiro: Cosac Naify, 2002.

VIVEIROS DE CASTRO, E. Who is afraid of the ontological wolf? Some comments on an ongoing anthropological debate. CUSAS Annual Marilyn Strathern Lecture. 2014. Acesso em 1 de Setembro de 2016. Disponível em: $>$ https://sisu.ut.ee/sites/default/files/biosemio/files/cusas_strathern_lecture_ 2014.pdf<.

Aprendiendo nuevos protocolos: El Akhulli, La Coca en la Diplomacia de los Pueblos. Ministerio de Relaciones Exteriores y Academia Diplomática Plurinacional. Bolivia, 2009. Disponível em: <http://atlas.umss.edu.bo:8o8o/xmlui/handle/123456789/1158>. Acesso em 1 de novembro 2016.

Buntland Report. World Commission on Environment and Development: Our Common Future. United Nations, 1987. Disponível em: <http://www.un.org/en/globalissues/environment/links.shtml>. Acesso em 1 de novembro 2016.

Constitución Política del Estado Boliviano. Cancillería de Bolivia, 2009. Disponível

em:<http://www.harmonywithnatureun.org/content/documents/159Bolivia\%2 oConsitucion.pdf> Acesso em 1 de novembro 2016.

Entrevista a Silvia Rivera Cusicanqui. Série Conversas del Mundo. La Paz, Bolivia, Direção de Fernando Vargas, 2014. Duração: 02:09:42. Disponível em: <https://www.youtube.com/watch?v=xjgHfSrLnpU>. Acesso em 20 de agosto 2016.

Ley de Derechos de la Madre Tierra. Estado Boliviano, 2010. Disponível em: <http://www.harmonywithnatureun.org/content/documents/158Bolivia\%20Le y\%20071.pdf $>$. Acesso em 1 de novembro 2016. 
Preámbulo de la Constitución Política de Ecuador. Cancillería de Ecuador. Disponível em: <http://cancilleria.gob.ec/wpcontent/uploads/2013/o6/constitucion_2008.pdf >. Acesso em 3 de novembro 2016.

Recebido em 09/11/2016. Aprovado em 18/12/2016. 